\title{
Research article \\ Computational modelling and analysis of Pyrimidine analogues as EGFR inhibitor in search of anticancer agents
}

\author{
Purra Buchi Reddy*1, Madhusudana Reddy M. B.*1, K. Ramakrishna Reddy ${ }^{1}$, Santosh S. Chhajed $^{2}$, and \\ Pramodkumar P. Gupta ${ }^{3}$ \\ ${ }^{1}$ Department of Chemistry, REVA University, Bangalore, Karnataka, India \\ ${ }^{2}$ Department of Pharmaceutical Chemistry, MET's Institute of Pharmacy, Nashik, Maharashtra, India \\ ${ }^{3}$ School of Biotechnology and Bioinformatics, D Y Patil Deemed to be University, Navi Mumbai, Maharashtra, India
}

(Received: December 2020

Revised: February 2021

Accepted: March 2021)

Corresponding authors: Purra Buchi Reddy. Email: buchip2017@gmail.com

Madhusudana Reddy M. B. Email: madhusudhana.mb@reva.edu.in

\begin{abstract}
Introduction and Aim: Epidermal Growth Factor Receptor tyrosine kinase is a well-known and widely studied cancer therapeutic target protein. Based on the reported anticancer activity of pyrimidines, a series of 13 compounds are designed. In the present study the EGFR kinase domain is targeted with the designed 13 compounds.

Materials and Methods: With missing residue in the kinase domain of EGFR crystallized structure, the domain is modelled using homology modelling, evaluated, energy-based optimization is carried out using OPLS in Gromacs. The default binding site was considered from the known EGFR kinase domain - Erlotinib complex crystallized structure. The molecular docking is carried out using Autodock Vina, Insilico toxicity profiling and enrichment analysis of pathway is studied using Swiss-ADME and Enrich R.

Results: Compounds 7, 9, 10 and 12 revealed a binding energy of $-8.8,-8.3,-8.3$ and $-8.4 \mathrm{Kcal} / \mathrm{mol}$ and makes two h-bonds with MET-769. All the 13 compounds are under the range of Lipnski drug likeness, with high GI-absorption rate. Considering the metabolic enzyme activity, the entire series of compounds are predicted to inhibit the metabolizing enzyme CYP1A2, CYP2D6 and CYP3A4. Compounds 2, 3, 7, 8 and 13 acts as a substrate to CYP2C19 and compound $1,3,4,5,6,7,8,9,10,11,12$ and 13 act as a substrate to CYP2C9.

Conclusion: The inhibition of metabolizing enzyme may affect the poor metabolizing and slowing down the excretion time of molecules from the body. The current in-silico molecular docking, in-silico PKPD study of compounds suggesting that they can be developed as putative lead compounds for developing new anti-cancer drugs.
\end{abstract}

Keywords: Pyrimidines; PKPD; molecular docking; toxicity prediction.

\section{INTRODUCTION}

$\mathrm{P}$ yrimidines have a long and distinguished history extending from the days of their discovery as important constituents of nucleic acids to their current use in the chemotherapy of AIDS. The pyrimidine ring is found in vitamins like thiamine and folic acid during the last two decades, several pyrimidine derivatives have been developed as chemotherapeutic agents and have found wide clinical applications. Antineoplastic and anticancer agents. There are a large number of pyrimidine-based antimetabolites. They are usually structurally related to the endogenous substrates that they antagonize. The structural modification may be on the pyrimidine ring or on the pendant sugar groups. One of the early metabolites prepared was 5 -fluorouracil, a pyrimidine derivative also exhibits some useful antineoplastic activities (1-3).

Pyrimidine is a useful structural motif for displaying potent antitumor activity. Several analogues of Pyrimidine are synthesized and tested for evaluating their anticancer activity. Due to promising anticancer activity exhibited by Pyrimidine, in the present manuscript attempt to design newer molecules which will exhibits useful anticancer activity. Attempt to design newer analogues by using Pyrimidine as pharmacophore with the hope that newer molecules will possess anticancer activity by inhibiting EGFR (Epidermal growth Factor Receptor) is described in the present manuscript. EGFR is kind of protein kinases, were proved to be a viable target for anticancer drug development (4-7). In addition, EGFR-TK is utmost important kinases that plays a fundamental role in signal transduction pathways (8). EGFR and its ligands, Epidermal Growth Factor [EGF] and transforming growth factor- $\alpha$ (TGF- $\alpha$ ) have been implicated in numerous tumors of epithelial origin $(8,9)$. Therefore, the design of inhibitors that target EGFR-TK is an attractive approach for design of new therapeutic agents.

\section{MATERIALS AND METHODS}

\section{Receptor preparation}

Receptor Epidermal Growth Factor Receptor tyrosine kinase domain was considered in the experiment. Due to missing residues in most of the 3D structure, we have adopted the homology modeling concept to model the 3D structure of EGFR kinase domain. Using 
Swiss-model server, the EGFR domain sequence is subjected to Swiss-model server and optimum homolog is selected for modeling. The modeled structure evaluated using Ramchandran plot and ProSA analysis. Further the structure was energy wise minimized using steepest method in Gromacs. The protein is solvated in water body (TIP3P model) in OPLS method and neutralized the system by adding $08 \mathrm{Na}^{+}$ions. Total 144973 molecules are subjected to energy minimization process, the potential energy, bonds, bond angles and prop-dihedral are evaluated for the stability purpose of the protein (10).

\section{Ligand sketching and optimization}

The selected 13 compound structures were sketched using Chemsketch tool version 12.0 and saved in .mol format. Using universal force field (UFF) using steepest descent algorithm all the 13 compounds are geometrically / energy wised optimized to attain their global lowest energy formed (11). Each compound is optimized up to it converged value by optimizing the bonds, angle, di-hedral and improper that depicted the lowest form of energy and finally saved in the pdb format

\section{Molecular docking}

We have autodock vina in autodock PyRx tool $(12,13)$. Here we have selected the default binding site region of Erlotinib the indigenous inhibitor of EGFR kinase with following pharmacophoric amino acids included in it LEU-694, LYS-721, MET-769, LEU-820, THR830 . The binding site size are as follows center value, X: 59.7232; Y: 48.5137; 51.1831with a dimension of $\mathrm{X}: 25$; Y: 25; Z: $25 \mathrm{~A}$. all the 13 compounds were loaded into the autodock PyRx tool and finally target protein EGFR kinase and compounds were converted to.pdbqt file format as a default input file format for autodock operations.

\section{Computational modeling of ADME properties}

The Drug development process imbibes the evaluation of absorption, distribution, metabolism and excretion (ADME). The ADME process highly dependent on physiological activity based model that includes the desired target association and dissociation (formation of bonds/selective interactions), blood brain permeation, toxicity, poor efficacy, interaction with metabolizing enzyme for clearance and off-target interactions, leading to toxicity and undesirable effect by penetrating significant metabolic pathways. Current insilico based modeling and analysis helps us to segregate the poor performer versus optimum and leads to early estimation of ADME based failure in the clinical phases. In the present work, we have predicted the ADMET properties of the 13 compounds were through SwissADME database, freely available at http://www.swissadme.ch/ (14).

Here, we have assessed the lipophilicity (lipophilicity, XLOGP3 between -0.7 and +5.0 ; size, MW between 150 and $500 \mathrm{~g} / \mathrm{mol}$; polarity, TPSA between 20 and $130 \AA$ A; solubility, $\log \mathrm{S}$ (calculated with the ESOL model) not higher than6; saturation, fraction of carbons in the sp3 hybridization not less than 0.25 ; and flexibility, no more than 9 rotatable bonds); drug likeness is calculated using Lipinski rule of five.

Elimination/excretion and toxicity for molecules were tested against the cytochromes P450 (CYP) and P-gp. The overexpression of P-gp in some tumor cells is well reported and leads to multidrug-resistant cancers, including a major role of P-gp which is to protect the central nervous system from xenobiotics. It is a wellknown fact that about 40 to $90 \%$ of drugs are substrate of five main isoforms (CYP1A2, CYP2C19, CYP2C9, CYP2D6, and CYP3A4). CYP and P- gp can process small molecules. Inhibition of these isozymes causes drug-drug interactions, toxicity, or unwanted side effects due to the lower clearance and accumulation of the drugs or its metabolites. Considering the predicted outcome for inhibition of CYP family enzymes, here we have perform the enrichment analysis to these CYP family enzymes and reported the metabolic pathways that might be affected by inhibition of these enzymes using EnrichR online enrichment analysis server $(15,16)$.

\section{RESULTS}

The target sequence exhibited a $100 \%$ homologous to 1M17.pdb a crystallized 3D structure with an inhibitor Erlotinib. The Ramchandran plot exhibited a $99.3 \%$ in most favored and favored region and $0.7 \%$ is in disallowed region (fig. 1A), ProSA analysis resulted the modeled structure in $\mathrm{x}$-ray crystallized zone supporting the high degree of good prediction of model with a Z-score of -6.76 (fig. $1 \mathrm{~B}$ ).

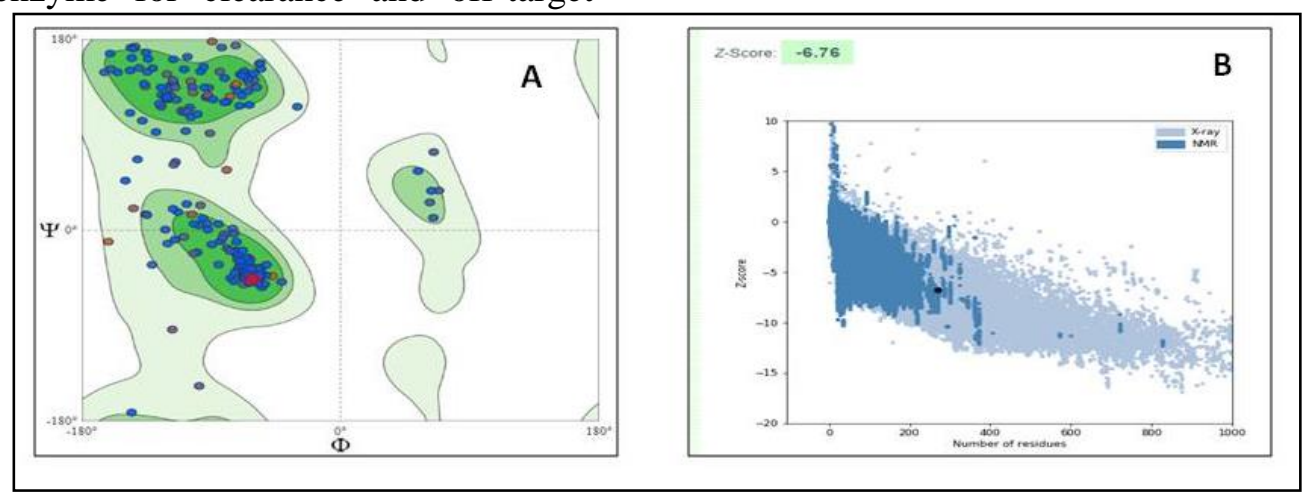

Fig. 1: Protein structure validation 
The energy minimized model of EGFR kinase domain exhibited a potential energy of $-2.5683860 \mathrm{e}+06$ under the Steepest Descents methods and converged to Fmax $<1000$ in 1925 steps. All the 04 parameters potential
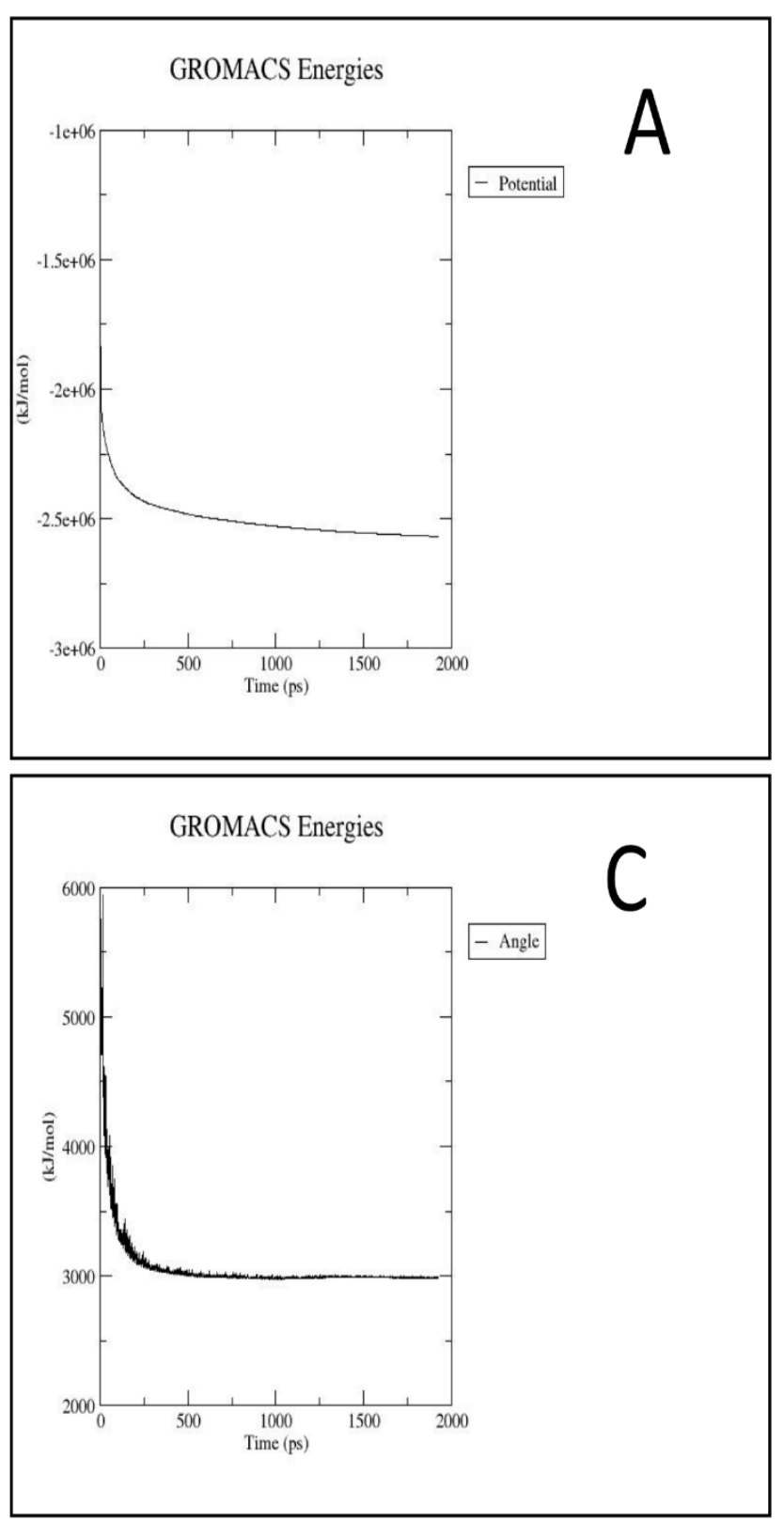

Fig. 2 A: Potential energy, B: Bond, C: Bond-angle, D: Proper-dihedral.

The RMSD between modeled structure versus the template (1M17.pdb) is $0.028 \mathrm{~A}$, and binding site region of the inhibitor is highly conserved in position (fig. 3).

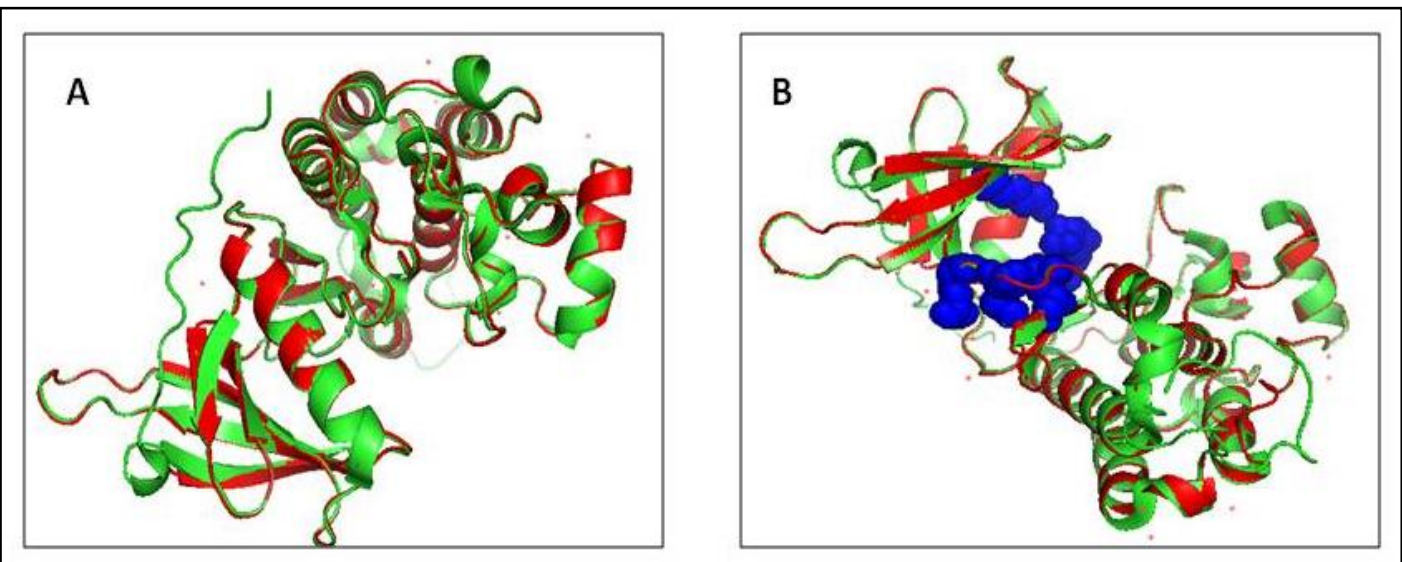

Fig. 3: The receptor model with superimposition and binding site residue 
The pyrimidine derivative was geometrical based optimized by converging the bonds, angle, dihedral, improper-torsion, Van-der Waals and Coulomb charges to their lowest energy form, results are summarized in table1 and final structures were subjected for further docking process.

Table 1: Ligand optimized energy

\begin{tabular}{|c|c|c|c|}
\hline Compound & Structure & $\begin{array}{c}\text { Initial Energy } \\
\text { Kcal/mol }\end{array}$ & $\begin{array}{c}\text { Final Energy } \\
\text { Kcal/mol }\end{array}$ \\
\hline Erlotinib & -- & 151.5661 & 38.49302 \\
\hline PYR1 & & 38919.73 & 708.3914 \\
\hline PYR 2 & & 39293.47 & 630.7075 \\
\hline PYR3 & & 42559.88 & 632.8202 \\
\hline PYR4 & & 39527.45 & 629.0926 \\
\hline PYR5 & & 39522.69 & 630.0523 \\
\hline PYR6 & & 47414.09 & 645.7556 \\
\hline PYR7 & & 49873.16 & 743.4329 \\
\hline PYR8 & & 36477.79 & 630.2922 \\
\hline PYR9 & & 36418.58 & 629.4352 \\
\hline PYR 10 & & 36819.1 & 627.9631 \\
\hline PYR 11 & & 67949.6 & 646.9463 \\
\hline PYR 12 & & 45223.8 & 562.8861 \\
\hline PYR 13 & & 25760.9 & 758.8053 \\
\hline
\end{tabular}


Here we have compared the molecular docking with standard inhibitor of EGFR, Erlotinib with our 13 synthesized compounds. The Erlotinib and EGFR molecular docked complex exhibited a binding energy of $-7.4 \mathrm{Kcal} / \mathrm{mol}$ similar interaction with $\mathrm{H}$-bond formation with MET-769 and placed within the binding site region additional interactions such h-bond formation with THR-766, GLN-767 and ASP-830, piinteraction with PHE-699 and VAL-702 is also reported.

In comparison to our synthesized 13 compounds all have acquired the binding site region with better binding energy with respect to Erlotinib, the binding energy ranges from $-7.5 \mathrm{Kcal} / \mathrm{mol}$ to $-8.8 \mathrm{Kcal} / \mathrm{mol}$.

Excluding compound 2 and 6 all are successful to make a h-bond interaction with MET-769. Compound
$7,9,10$ and 12 makes revealed a binding energy of $8.8,-8.3,-8.3$ and $-8.4 \mathrm{Kcal} / \mathrm{mol}$ and makes two hbonds with MET-769 as common to all and rest with either of the listed amino acid residues GLU-738 and THR-766 (fig. 4). Compound 3, 4, 5, 8 and 11 stated a binding energy of $-7.9,-8.2,-8.3,-8.1$ and -8.0 forms three $\mathrm{H}$-bond interactions, MET-769 is common in all and rest two with either of the listed amino acid residues: LEU-694, GLU-738, THR-766, GLN-767, ASP-831. Compound 1 and 13 exhibited a binding energy of -8.0 and $-7.5 \mathrm{Kcal} / \mathrm{mol}$ with $\mathrm{h}$-bond formation with GLU-738, THR-766, MET-769, CYS773 , all the pharmacophoric based interaction including H-bonds, Pi interaction and Vander-Waal interactions are listed in table 2.

Table 2: Molecular docking results

\begin{tabular}{|c|c|c|c|c|}
\hline Compound & Binding Affinity & H-Bond & pi-interaction & Vander-Waal-interaction \\
\hline Erlotinib & -7.4 & $\begin{array}{l}\text { THR-766, } \\
\text { GLN-767, } \\
\text { MET-769, } \\
\text { THR-830 }\end{array}$ & $\begin{array}{l}\text { PHE-699, VAL- } \\
702\end{array}$ & $\begin{array}{l}\text { LEU-694, GLY-695, ALA-719, LYS-721, } \\
\text { GLU-738, MET-742, CYS-751, LEU-768, } \\
\text { GLY-772, ARG-817, ASN-818, ASP-831, } \\
\text { GLY-833 }\end{array}$ \\
\hline PYR 1 & -8 & $\begin{array}{l}\text { GLU-738, } \\
\text { THR-766, } \\
\text { MET-769, } \\
\text { CYS-773 }\end{array}$ & $\begin{array}{l}\text { LEU-694, VAL- } \\
\text { 702, ALA-719, } \\
\text { LYS-721, LEU- } \\
820\end{array}$ & $\begin{array}{l}\text { GLY-695, PHE-699, ILE-720, MET-742, } \\
\text { CYS-751, LEU-764, GLN-767, LEU-768, } \\
\text { PRO-770, GLY-772, THR-830, ASP-831. }\end{array}$ \\
\hline PYR 2 & -8.2 & $\begin{array}{l}\text { ARG-817, } \\
\text { ASN-818, } \\
\text { THR-830, } \\
\text { ASP-831 }\end{array}$ & $\begin{array}{l}\text { PHE-699, VAL- } \\
\text { 702, ALA-719, } \\
\text { LEU-820, ASP- } \\
831\end{array}$ & $\begin{array}{l}\text { GLY-695, SER-696, GLY-697, LYS-721, } \\
\text { GLU-738, MET-742, CYS-751, LEU-764, } \\
\text { GLN-767, LEU-768, MET-769, CYS-773, } \\
\text { VAL-819, ASP-831 }\end{array}$ \\
\hline PYR 3 & -7.9 & $\begin{array}{l}\text { GLU-738, } \\
\text { THR-766, } \\
\text { MET-769 }\end{array}$ & $\begin{array}{l}\text { LEU-694, VAL- } \\
\text { 702, ALA-719, } \\
\text { LYS-721, LEU- } \\
820\end{array}$ & $\begin{array}{l}\text { GLY-695, SER-696, PHE-699, ILE-720, } \\
\text { CYS-751, LEU-753, LEU-764, GLN-767, } \\
\text { LEU-768, PRO-770, GLY-772, THR-830, } \\
\text { ASP-831. }\end{array}$ \\
\hline PYR 4 & -8.2 & $\begin{array}{l}\text { GLN-767, } \\
\text { MET-769, } \\
\text { ASP-831 }\end{array}$ & $\begin{array}{l}\text { LEU-694, VAL- } \\
\text { 702, ALA-719, } \\
\text { LYS-721, LEU- } \\
\text { 820, ASP-831 }\end{array}$ & $\begin{array}{l}\text { PHE-699, LYS-704, CYS-751, THR-766, } \\
\text { LEU-768, PRO-770, PHE-771, GLY-772, } \\
\text { THR-830. }\end{array}$ \\
\hline PYR 5 & -8.3 & $\begin{array}{l}\text { GLU-738, } \\
\text { THR-766, } \\
\text { MET-769 }\end{array}$ & $\begin{array}{l}\text { LEU-694, VAL- } \\
\text { 702, ALA-719, } \\
\text { LYS-721, LEU- } \\
\quad 820\end{array}$ & $\begin{array}{l}\text { GLY-695, SER-696, PHE-699, ILE-720, } \\
\text { MET-742, CYS-751, LEU-753, LEU-764, } \\
\text { GLN-767, LEU-768, PRO-770, GLY-772, } \\
\text { THR-830, ASP-831. }\end{array}$ \\
\hline C PYR 6 & -8.4 & $\begin{array}{l}\text { ARG-817, } \\
\text { ASN-818, } \\
\text { THR-830, } \\
\text { ASP-831 }\end{array}$ & $\begin{array}{l}\text { LEU-694, VAL- } \\
\text { 702, ALA-719, } \\
\text { LYS-721, MET- } \\
\text { 742, LEU-820 }\end{array}$ & $\begin{array}{l}\text { LEU-694, PHE-699, VAL-702, ILE-720, } \\
\text { GLU-738, MET-742, CYS-751, LEU-753, } \\
\text { LEU-764, GLN-767, LEU-768, PRO-770, } \\
\text { GLY-772, ARG-817, LEU-820, ASP-831 }\end{array}$ \\
\hline PYR 7 & -8.8 & $\begin{array}{l}\text { THR-766, } \\
\text { MET-769 }\end{array}$ & $\begin{array}{c}\text { ALA-719, LYS- } \\
721\end{array}$ & $\begin{array}{l}\text { GLY-695, PHE-699, ILE-720, CYS-751, } \\
\text { LEU-753, LEU-764, GLN-767, LEU-768, } \\
\text { PRO-770, GLY-772, CYS-773, THR-830, } \\
\text { ASP-831, PHE-832 }\end{array}$ \\
\hline PYR 8 & -8.1 & $\begin{array}{l}\text { LEU-694, } \\
\text { THR-766, } \\
\text { MET-769 }\end{array}$ & $\begin{array}{l}\text { LEU-694, VAL- } \\
\text { 702, ALA-719, } \\
\text { LYS-721, LEU- } \\
\quad 820\end{array}$ & $\begin{array}{l}\text { GLY-695, SER-696, PHE-699, ILE-720, } \\
\text { GLU-738, MET-742, CYS-751, LEU-753, } \\
\text { LEU-764, GLN-767, LEU-768, PRO-770, } \\
\text { GLY-772, THR-830, ASP-831 }\end{array}$ \\
\hline PYR 9 & -8.3 & $\begin{array}{l}\text { THR-766, } \\
\text { MET-769 }\end{array}$ & $\begin{array}{l}\text { LEU-694, VAL- } \\
\text { 702, ALA-719, } \\
\text { LYS-721, LEU- } \\
820 \\
\end{array}$ & $\begin{array}{l}\text { GLY-695, SER-696, PHE-699, ILE-720, } \\
\text { MET-742, CYS-751, LEU-753, LEU-764, } \\
\text { GLN-767, LEU-768, PRO-770, GLY-772, } \\
\text { THR-830, ASP-831 }\end{array}$ \\
\hline PYR 10 & -8.3 & $\begin{array}{l}\text { GLU-738, } \\
\text { MET-769 }\end{array}$ & $\begin{array}{l}\text { LEU-694, PHE- } \\
\text { 699, VAL-702, }\end{array}$ & $\begin{array}{l}\text { GLY-695, GLY-697, ILE-720, CYS-751, } \\
\text { LEU-753, LEU-764, GLN-767, LEU-768, } \\
\text { PRO-770, GLY-772, THR-830 }\end{array}$ \\
\hline
\end{tabular}




\begin{tabular}{|c|c|c|c|c|}
\hline & & & $\begin{array}{c}\text { ALA-709, LYS- } \\
\text { 721, LEU-820 }\end{array}$ & \\
\hline PYR 11 & -8 & $\begin{array}{l}\text { THR-766, } \\
\text { MET-769, } \\
\text { CYS-773 }\end{array}$ & $\begin{array}{l}\text { LEU-694, VAL- } \\
\text { 702, ALA-719, } \\
\text { LYS-721, MET- } \\
\text { 742, LEU-820 }\end{array}$ & $\begin{array}{l}\text { GLY-695, PHE-699, ILE-720, GLU-738, } \\
\text { CYS-751, LEU-753, LEU-764, GLN-767, } \\
\text { PRO-770, GLY-772, THR-830, ASP-831 }\end{array}$ \\
\hline PYR 12 & -8.4 & $\begin{array}{l}\text { THR-766, } \\
\text { MET-769 }\end{array}$ & $\begin{array}{l}\text { LEU-694, PHE- } \\
\text { 699, VAL-702, } \\
\text { ALA-709, LYS- } \\
\text { 721, LEU-820 }\end{array}$ & $\begin{array}{l}\text { GLY-695, SER-696, GLY-697, ILE-720, } \\
\text { GLU-738, MET-742, CYS-751, LEU-753, } \\
\text { LEU-764, LEU-768, PRO-770, GLY-772, } \\
\text { THR-830, ASP-831 }\end{array}$ \\
\hline PYR 13 & -7.5 & $\begin{array}{l}\text { GLU-738, } \\
\text { THR-766, } \\
\text { MET-769, } \\
\text { CYS-773 }\end{array}$ & $\begin{array}{l}\text { VAL-702, ALA- } \\
\text { 719, LYS-721, } \\
\text { MET-742, LEU- } \\
820\end{array}$ & $\begin{array}{l}\text { LEU-694, ILE-720, CYS-751, LEU-750, } \\
\text { LEU-764, GLN-767, LEU-768, PRO-770, } \\
\text { GLY-772, THR-830, ASP-831 }\end{array}$ \\
\hline
\end{tabular}

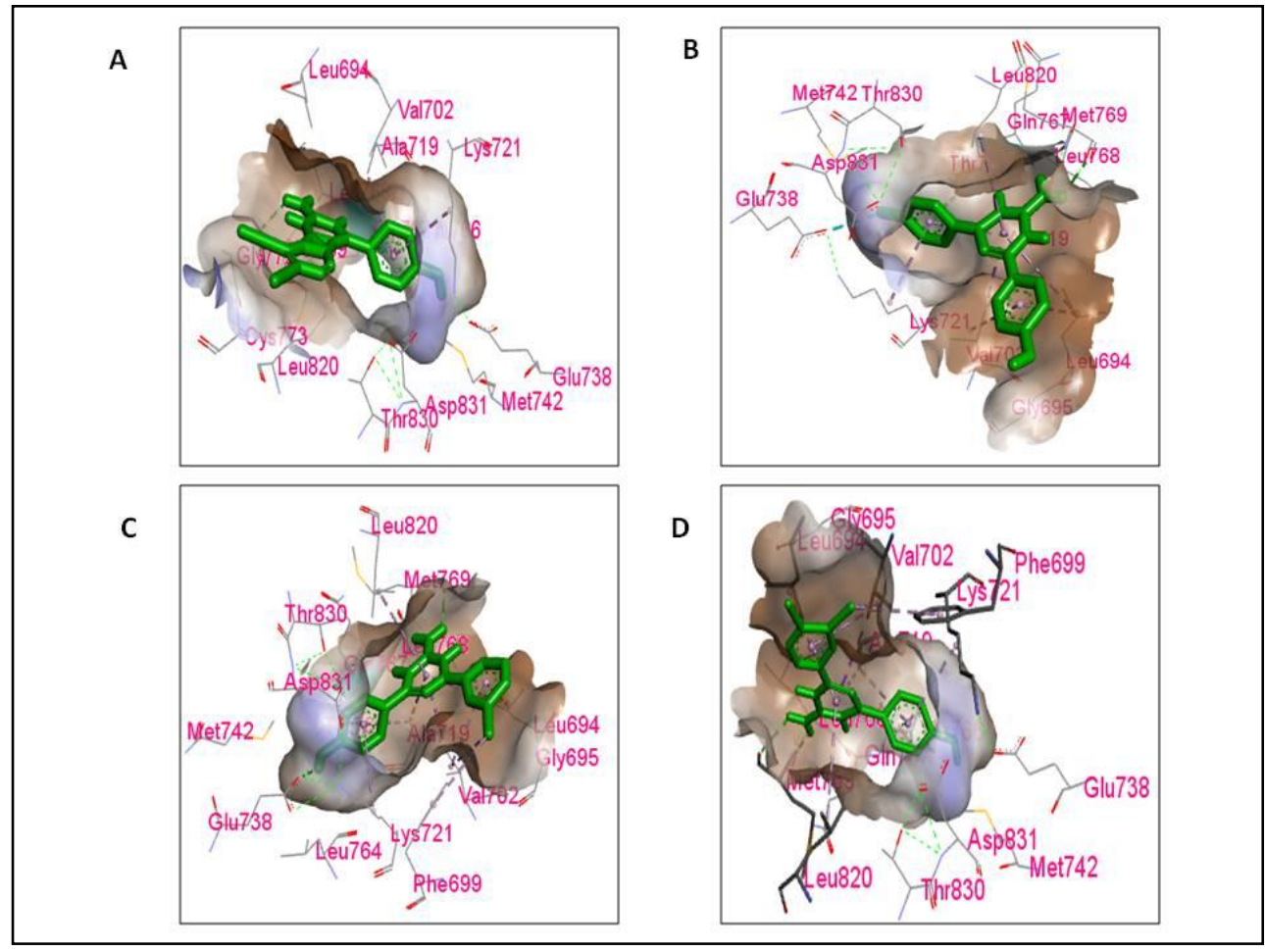

Fig. 4: Molecular docking results with interactions

A: Compound 7 forms hydrogen bonding interactions with amino acids THR-766, MET-769 and pi-interactions with amino acid residues ALA-719, LYS-721

B: Compound 9 forms hydrogen bond interactions with THR-766, MET-769 and pi interactions LEU-694, VAL-702, ALA-719, LYS-721, LEU-820

C: Compound 10: forms hydrogen bonding interactions with amino acids GLU-738, MET-769, pi-interactions pi interactions with amino acids LEU-694, PHE-699, VAL-702, ALA-709, LYS-721, LEU-820

D: Compound 12 forms hydrogen bonding interactions with amino acids THR-766, MET-769 and pi-interactions with amino acids LEU-694, PHE-699, VAL-702, ALA-709,

LYS-721, LEU-820

\section{Computational modeling / based drug likeness and} toxicity

In order to reduce the cost, time and late failure of compound and gain early estimation of true positive results we have performed in-silico based ADME analysis. All the 13 compounds were subjected to Swiss-ADME online server for their drug likeness and toxicity prediction. All the 13 compounds revealed a lipophilicity value range between 1.92 to 4.21; Molecular weight range between 253.26 to 332.18 ; Total polar surface area (TPSA) range between 72.03 to $117.85 \mathrm{~A}$; ESOL (Log S) range between -4.94 to 3.15 , considering the flexibility of structure the 13 compounds range minimum 2 and maximum 4 rotatable bonds followed by maximum $5 \mathrm{~h}$-bonds acceptors and 2 hydrogen bond donors exhibits that the designed compounds could posses a good oral bioavailability (ADME data - Supplementary). GIabsorption is high to all the designed 13 compounds, compound 1, 3, 9, 1011 and 12 are permeable to Blood Brain Barrier. Compound 1, 3,4,5,6,7,8,9, 11 and 13 are substrate to Pgp. None of the compound violate Lipinski filter.

Further assessing the metabolic factor here we analyze the selected compounds with CYP family enzymes and perform their enrichment analysis. The entire 13 
compounds act as an inhibitor to CYP1A2, CYP2D6 and CYP3A4. Inhibition of CYP1A2 may affect the following pathway and their related biological functions such as the caffeine metabolism, Linoleic acid metabolism, Tryptophan metabolism, Steroid hormone biosynthesis, Retinol metabolism, Metabolism of xenobiotics by cytochrome P450, Chemical carcinogenesis and Drug metabolism. For CYP2D66 the Metabolism of xenobiotics by cytochrome P450, Drug metabolism and Serotonergic synapse. In case inhibition of CYP3A4 the Linoleic acid metabolism, Steroid hormone biosynthesis, Retinol metabolism, Bile secretion, Metabolism of xenobiotics by cytochrome P450, Chemical carcinogenesis and Drug metabolism (fig. 5).
Compound 2, 3, 7, 8 and 13 act as a substrate to CYP2C19, inhibition of CYP2C19 may affect following metabolic pathway and biological function such as the Linoleic acid metabolism, Arachidonic acid metabolism, Chemical carcinogenesis, Drug metabolism and Serotonergic synapse. Compound 1, $3,4,5,6,7,8,9,10,11,12$ and 13 act as a substrate to CYP2C9, inhibition of CYP2C9 may affect the Linoleic acid metabolism, Arachidonic acid metabolism, Retinol metabolism, Metabolism of xenobiotics by cytochrome P450, Chemical carcinogenesis, Drug metabolism and Serotonergic synapse (fig. 6).

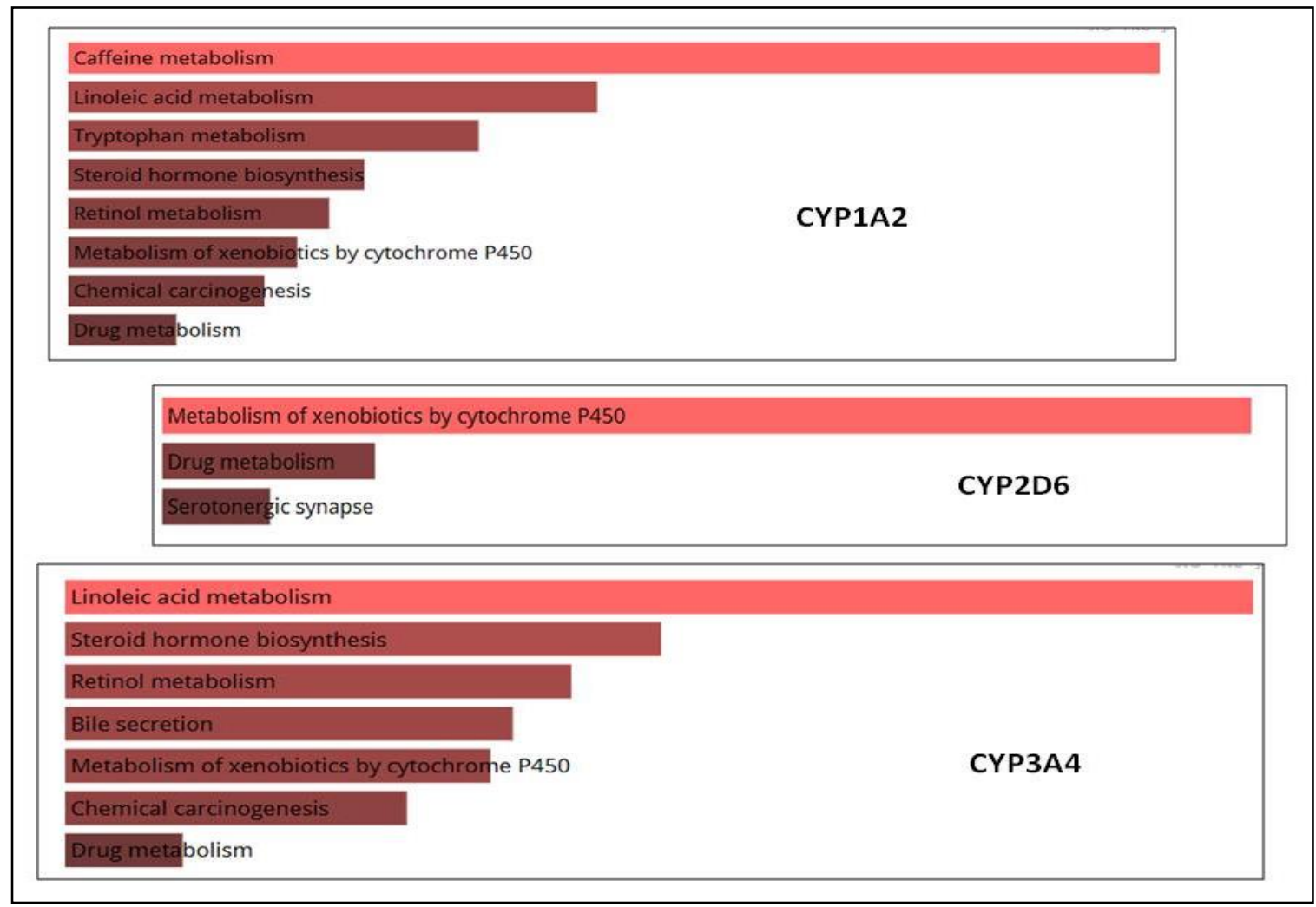

Fig. 5: Metabolic pathway involved via CYP1A2, CYP2D6 and CYP3A4

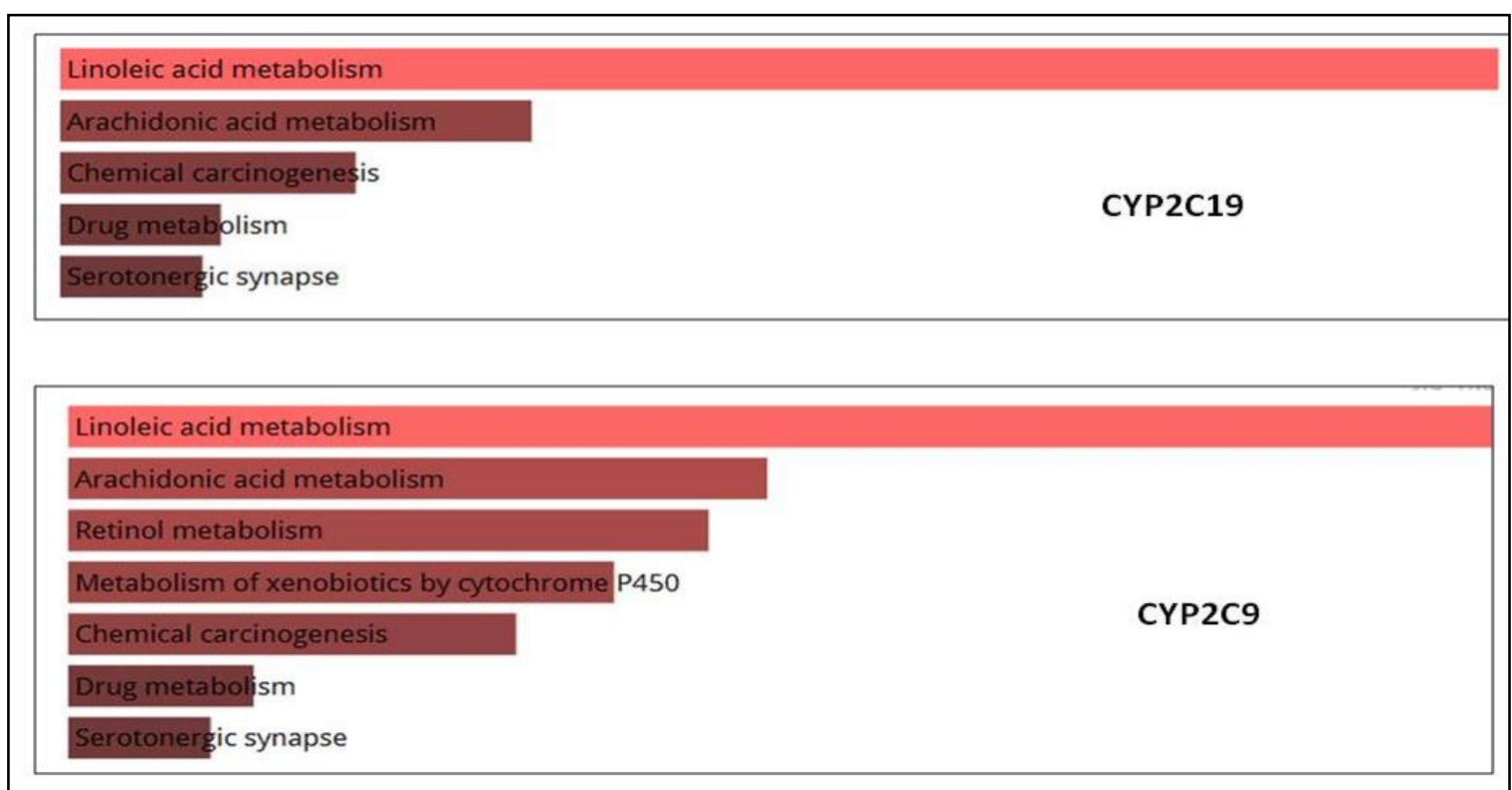

Fig. 6: Metabolic pathway involved via CYP2C19 and CYP2C9 


\section{DISCUSSION}

Compounds well known as pyrimidine derivatives are well explored and studied for their anticancer activity by targeting the EGFR wild type and mutants $(17,18)$. Numerous curcumin analogues containing pyrimidine ring are effective in inhibition of EGFR and evaluated by in-silico methodology (19). Pyrimidine analogues are also well studied for their dual inhibition roles like ATX and EGFR (20) as well as for EGFR/HER2 and well supported by molecular docking and interactions based study $(21,22)$. Out of the 13 designed pyrimidine analogues, Compound 07, 09, 10 and 12 exhibited a good degree of binding interactions within the EGFR binding pocket (fig. 7). The in-silico based<smiles>COc1ccc(-c2cc(-c3ccc(O)cc3)nc(N)n2)cc1OC</smiles><smiles>Nc1nc(-c2ccc(O)cc2)cc(-c2cccc(Cl)c2)n1</smiles>

drug likeness and PKPD analysis supported high degree of GI-absorption rate and highly commendable to the Lipinski filter shows the drug-able activity. As all the designed compounds exhibited as an inhibitor to CYP1A2, CYP2D6 and CYP3A4 suggests they may affect some of the essential biological pathway. Whereas they also act as a substrate to the other metabolic enzyme reveals the signal of metabolizing of these compounds further and may excrete via appropriate mechanism. Some of the compounds holds a strong binding affinity, better outcome from insilico toxicity profiling and pathway analysis and can be further studied for biological evaluations.<smiles>Nc1nc(-c2ccc(O)cc2)cc(-c2ccc(F)cc2)n1</smiles><smiles>Nc1nc(-c2ccc(Cl)cc2)cc(-c2ccc(Cl)c(Cl)c2)n1</smiles>

Fig. 7: Compounds identified as optimum and hence putative lead

\section{CONCLUSION}

In conclusion, the 3D structure of EGFR kinase domain resulted a $99.3 \%$ in most favored and favored region and $0.7 \%$ is in disallowed region of Ramachandran plot that shows a highly acceptable range of structure. All the designed compounds exhibited a good docking score in comparison to the indigenous inhibitor Erlotinib, including a highly similar pharmacophoric interactions pattern, where compound 7, 9,10 and 12 are optimum. The outcomes from the insilico toxicity profiling and pathway analysis resulted few compounds to be further studied and evaluate for more parameters in terms of their biological evaluation in in-vivo and in-vitro condition. The present work suggests that the current studied compounds can be considered as putative lead compounds for developing new anti-cancer drugs.

\section{CONFLICT OF INTEREST}

The authors declare there is no conflict of interest.

\section{REFERENCES}

1. Vogel, S., Ohmayer, S., Brunner, G., Heilmann, J. Natural and non-natural prenylated chalcones: Synthesis, cytotoxicity and anti-oxidative activity. Bioorg Med Chem. 2008 Apr; 16(8): 4286-4293.

2. Azam, M., Kumar, B. R., Shalini, S., Suresh, B., Reddy, T., Reddy, C. Synthesis and biological screening of $5-\{[(4,6-$ disubstituted pyrimidine-2-yl) thio]methyl \}-N-phenyl-1,3,4thiadiazol-2-amines. Indian J Pharm Sci. 2008; 70(5): 672.

3. Gangjee, A., Kurup, S., Ihnat, A., Thorpe, J. E., Shenoy, S. S. Synthesis and biological activity of N4-phenylsubstituted-6(2,4-dichloro phenylmethyl)-7H-pyrrolo[2,3-d]pyrimidine2,4-diamines as vascular endothelial growth factor receptor2 inhibitors and antiangiogenic and antitumor agents. Bioorg Med Chem. 2010 May; 18(10): 3575-3587.

4. Wu, K, W., Chen, P. C., Wang, J., Sun, Y-C. Computation of relative binding free energy for an inhibitor and its analogs binding with Erk kinase using thermodynamic integration MD simulation. J. Comput Aided Mol Des. 2012 Oct 18; 26(10): 1159-1169.

5. Levitzki, A. Tyrosine kinase inhibitors: views of selectivity, sensitivity, and clinical performance. Annu Rev Pharmacol Toxicol. 2013; 53: 161-185.

6. Roymans, D., Slegers, H. Phosphatidylinositol 3-kinases in tumor progression. Eur J Biochem. 2001 Feb; 268(3): 487498.

7. Malumbres, M., Barbacid, M. Cell cycle kinases in cancer. Curr Opin Genet Dev. 2007 Feb; 17(1): 60-65.

8. Ullrich, A., Schlessinger, J. Signal transduction by receptors with tyrosine kinase activity. Cell. 1990 Apr 20; 61(2): 203212.

9. Chhajed, S. S., Shinde, P. E., Kshirsagar, S. J., Sangshetti, J. N., Gupta, P. P. De-novo design and synthesis of conformationally restricted thiazolidine-2,4-dione analogues: highly selective PPAR- $\gamma$ agonist in search of anti-diabetic agent. Struct Chem. 2020 Aug 17; 31(4): 1375-1385.

10. Abraham, M. J., Murtola, T., Schulz, R., Páll, S., Smith, J. C., Hess, B. GROMACS: High performance molecular simulations through multi-level parallelism from laptops to supercomputers. SoftwareX. 2015;1(2):19-25. 
11. Rappe, A. K., Casewit, C. J., Colwell, .K. S., Goddard, W. A., Skiff W. M. UFF, a full periodic table force field for molecular mechanics and molecular dynamics simulations. J Am Chem Soc. 1992 Dec; 114(25): 10024-10035.

12. Trott, O., Olson, A. J. AutoDock Vina: Improving the speed and accuracy of docking with a new scoring function, efficient optimization, and multithreading. J Comput Chem. 2009; NA-NA.

13. Dallakyan, S., Olson, A.J. Small-Molecule Library Screening by Docking with PyRx. In 2015; 243-250.

14. Daina, A., Michielin, O., Zoete, V. SwissADME: a free web tool to evaluate pharmacokinetics, drug-likeness and medicinal chemistry friendliness of small molecules. Sci Rep. 2017; 7: 42717.

15. Kuleshov, M. V., Jones, M. R., Rouillard, A. D. Fernandez N. F., Duan, Q., Wang, Z., et al., Enrichr: a comprehensive gene set enrichment analysis web server 2016 update. Nucleic Acids Res. 2016 Jul 8; 44(1): 90-97.

16. Chen, E. Y., Tan, C. M., Kou, Y., Duan, Q., Wang, Z., Meirelles, G. Enrichr: interactive and collaborative HTML5 gene list enrichment analysis tool. BMC Bioinformatics. 2013; 14(1): 128.

17. Gaber, A. A., Bayoumi, A. H., El-Morsy, A. M., Sherbiny, F. F., Mehany, A. B. M., Eissa, I. H. Design, synthesis and anticancer evaluation of 1H-pyrazolo[3,4-d]pyrimidine derivatives as potent EGFRWT and EGFRT790M inhibitors and apoptosis inducers. Bioorg Chem. 2018; 80: 375-395.

18. Adly, M. E., Gedawy, E. M., El-Malah, A. A., El-Telbany, F. A. Synthesis of Novel Thieno[2,3-d]pyrimidine derivatives and evaluation of their cytotoxicity and EGFR inhibitory activity. Anticancer Agents Med Chem. 2018; 18(5): 747756.

19. Ahsan, M. J., Khalilullah, H., Yasmin, S., Jadav, S. S., Govindasamy J. Synthesis, characterisation, and in vitro anticancer activity of curcumin analogues bearing pyrazole/pyrimidine ring targeting EGFR tyrosine kinase. Biomed Res Int. 2013; 2013: 1-14.

20. Jing, T., Miao, X., Jiang, F., Guo, M., Xing, L., Zhang, J. Discovery and optimization of tetrahydropyrido[4,3d]pyrimidine derivatives as novel ATX and EGFR dual inhibitors. Bioorg Med Chem. 2018 May; 26(8): 1784-1796.

21. Elmetwally, S. A., Saied, K. F., Eissa, I. H., Elkaeed, E. B. Design, synthesis and anticancer evaluation of thieno[2,3d]pyrimidine derivatives as dual EGFR/HER2 inhibitors and apoptosis inducers. Bioorg Chem. 2019 Jul; 88: 102944.

22. Milik, S. N., Abdel-Aziz, A. K., Lasheen, D. S., Minucci, S. Abouzid, K. A. M. Surmounting the resistance against EGFR inhibitors through the development of thieno[2,3d]pyrimidine-based dual EGFR/HER2 inhibitors. Eur J Med Chem. 2018 Jul; 155: 316-336. 